Check for updates

Cite this: RSC Adv., 2018, 8, 7558

Received 3rd January 2018

Accepted 13th February 2018

DOI: $10.1039 / \mathrm{c} 8 \mathrm{ra00056e}$

rsc.li/rsc-advances

\section{The effect of metallic Fe(II) and nonmetallic S codoping on the photocatalytic performance of graphitic carbon nitride}

\author{
Hailong Dou, Shaohui Zheng (D) and Yongping Zhang (D) *
}

\begin{abstract}
The metallic Fe(॥) ion and nonmetallic $\mathrm{S}$ codoped $\mathrm{g}-\mathrm{C}_{3} \mathrm{~N}_{4}$ photocatalyst was synthesized through the polymerization of melamine, ferrous chloride and trithiocyanuric acid (TCA) at elevated temperature. The performance of $\mathrm{Fe}(\|)-\mathrm{S}$ codoped $\mathrm{g}-\mathrm{C}_{3} \mathrm{~N}_{4}$ compounds in $\mathrm{RhB}$ photocatalytic degradation was found to increase 5 times. This significant enhancement in catalytic activity is probably related to the enhanced visible light adsorption and the mobility of photoinduced electron/hole pairs, attributable to bandgap narrowing and also lowering in the surface electrostatic potential compared to that of the pure g- $\mathrm{C}_{3} \mathrm{~N}_{4}$ nanosheets. XRD and XPS results indicate that the Fe species binds with $\mathrm{N}$-atoms to form $\mathrm{Fe}-\mathrm{N}$ bonds in the state of Fe(॥) ions. Fe(॥) doping increases the specific surface area, and enhances the photoinduced electron/hole pairs illustrated by PL, EIS spectra and transient photocurrent response measurements. The theoretical results show that divalent Fe(II) ions coordinating in the pore centre among three triazine units form discrete dopant bands and $\mathrm{S}$ dopants substituting the $\mathrm{N}$ in triazine skeletons excite much stronger delocalized HOMO and LUMO states, facilitating the migration of photogenerated charge carriers, thus enhancing the visible-light driven photocatalytic performance.
\end{abstract}

\section{Introduction}

Pollutant degradation and clean energy generation through semiconductor photocatalysis have been important research topics. Photocatalysis provides certain promising approaches in water splitting for $\mathrm{H}_{2}$ evolution and pollutant degradation using solar energy directly and aroused considerable interest from research experts in materials science and chemistry. It is a green technology to decompose pollutants into innocuous molecules via photocatalysis, without secondary pollution. However, there are still several challenges, including low quantum efficiency and insufficient visible light adsorption of photocatalysts.

The visible light photocatalysts based on graphene have drawn great attention due to their good absorption performance, excellent electrical conductivity and high specific surface area. ${ }^{1-4}$ However, the application of $2 \mathrm{D}$ graphene is hindered by its zero band gap. The graphitic carbon nitride ( $\mathrm{g}$ $\mathrm{C}_{3} \mathrm{~N}_{4}$ ) has layered structure similar to graphene and possesses an appropriate band structure and bandgap of $2.7 \mathrm{eV}$ allowing it to serve as a visible light driven photocatalyst for solar energy conversion. It was found to have potential applications in water splitting to generate $\mathrm{H}_{2}$, pollutant degradation and $\mathrm{CO}_{2}$ reduction. $^{5-8}$ The major issue related to $\mathrm{g}^{-} \mathrm{C}_{3} \mathrm{~N}_{4}$ is the rapid combination of the photoinduced charge carriers, resulting in a low quantum efficiency of photocatalytic reactions.

Faculty of Materials and Energy, Southwest University, Chongqing 400715, China. E-mail: zhangyyping@yahoo.com
Great endeavors have been made to improve the performance of $\mathrm{g}-\mathrm{C}_{3} \mathrm{~N}_{4}$ ever since its emergence as a photocatalyst. One strategy was to fabricate nano/mesoporous structures with a soft or hard template, ${ }^{9-12}$ further increasing the specific surface area, and thus improving the photon absorption in the visible light region. Another was to engineer the band structures of g- $\mathrm{C}_{3} \mathrm{~N}_{4}$ catalysts to separate the electron/hole pair effectively by coupling with metal particles, ${ }^{13-15}$ doping metal or non-metal elements, ${ }^{16-20}$ and forming heterojunction with other semiconductors, such as $\mathrm{ZnO}$, $\mathrm{CuO}, \mathrm{TiO}_{2}$ and $\mathrm{CdS},{ }^{21-24}$ etc. The studies of doping elements in $\mathrm{g}-\mathrm{C}_{3} \mathrm{~N}_{4}$ revealed that anion ion doping tunes the conduction band through the hybridization of p-orbitals of doped element with the p-orbitals of matrix carbon nitride, while cations adjusts the valence band by generating a discrete band via 3d orbitals of transition metal elements. Anion and cation codoping may enable us to modify the conduction and valence bands simultaneously, thus tuning the bandgap. Meanwhile, anion and cation codoping maintains the charge balance in the $\mathrm{g}_{-} \mathrm{C}_{3} \mathrm{~N}_{4}$ nanosheets, and stabilizes its photocatalytic performance. In practice, complexity occurs in specific cases related to different doping sites and variation of valence state of transition metal elements. Therefore, further experimental and theoretical investigations are essential to develop high performance catalysts and gain deeper insight into the mechanism of the enhanced photocatalytic performance via metal and nonmetal element codoping.

In this paper, we synthesized a Fe(II) and S codoped g- $\mathrm{C}_{3} \mathrm{~N}_{4}$ photocatalyst by calcifying melamine, ferrous chloride and 
trithiocyanuric acid and expatiated its mechanism by intertwining experimental observation and theoretical calculation. The experimental results reveal that the $\mathrm{Fe}(\mathrm{II})-\mathrm{S}$ codoped g- $\mathrm{C}_{3} \mathrm{~N}_{4}$ exhibits superior photodegradation for RhB under visible light irradiation. Density functional theory (DFT) calculations demonstrate that the $\mathrm{Fe}(\mathrm{II})$ and $\mathrm{S}$ doping reduces the bandgap and increases the reactive sites, facilitating the transfer of photogenerated electron-hole pairs.

\section{Experimental details}

\subsection{Synthesis of the pure, $\mathrm{Fe}(\mathrm{II})$ doped, $\mathrm{Fe}(\mathrm{II})-\mathrm{S}$ codoped $\mathrm{g}$ - $\mathrm{C}_{3} \mathbf{N}_{4}$}

All chemicals used herein were analytical grade and used without further purification. Melamine $\left(\mathrm{C}_{3} \mathrm{H}_{6} \mathrm{~N}_{6}, \geq 99.5 \%\right)$, ferrous chloride ( $\left.\mathrm{Fe}(\mathrm{II}) \mathrm{Cl}_{2}, \geq 99 \%\right)$, and trithiocyanuric $\left(\mathrm{C}_{3} \mathrm{H}_{3} \mathrm{~N}_{3} \mathrm{~S}_{3}, \geq 95 \%\right)$ were supplied by Sinopharm Chemical Reagent Co. Ltd.

In the typical experiment, iron(II) chloride ( $\mathrm{Fe}(\mathrm{II}) \mathrm{Cl}_{2}, 0.13 \mathrm{~g}$ ) was dissolved into $20 \mathrm{~mL} 3 \mathrm{M}$ nitric acid. Then the solution was fully mixed with $3 \mathrm{~g}$ melamine (dissolved in $60 \mathrm{~mL}$ methanol solution with $50 \%$ water) inside a beaker and dried at $60{ }^{\circ} \mathrm{C}$ overnight. The resulting white substance of $2.52 \mathrm{~g}$ was mixed with $1.77 \mathrm{~g}$ trithiocyanuric acid (TCA). The mixture was ground into powders, transferred to a silica crucible with cover, and then heated at $550{ }^{\circ} \mathrm{C}$ for $2 \mathrm{~h}$ under nitrogen environment. The resulting yellow powders were ground to produce $\mathrm{Fe}(\mathrm{II})-\mathrm{S}$ codoped g- $\mathrm{C}_{3} \mathrm{~N}_{4}$ samples (denoted as $\mathrm{Fe}(\mathrm{II} / \mathrm{S}-\mathrm{g}$-CN). The $\mathrm{Fe}(\mathrm{II})$ doped $\mathrm{g}-\mathrm{C}_{3} \mathrm{~N}_{4}$ ( $\mathrm{Fe}(\mathrm{II})-\mathrm{g}$ - $\left.\mathrm{CN}\right)$ was prepared in the same way without TCA involved in the preparation process. The pure g$\mathrm{C}_{3} \mathrm{~N}_{4}$ (g-CN) was synthesized by thermally heating melamine (M) powder $(2.56 \mathrm{~g})$ at $550{ }^{\circ} \mathrm{C}$ for $2 \mathrm{~h}$ under nitrogen atmosphere.

\subsection{Characterization}

Surface morphologies of the prepared samples were investigated using a scanning electron microscope (SEM, JSE-7800F, Jeol). Their crystalline structures were characterized by X-ray diffraction (XRD) patterns obtained using Shimadzu XRD7000 with $\mathrm{Cu} \mathrm{K} \alpha$ radiation $(\lambda=1.5418 \AA)$. Fourier transform infrared spectroscopic study (FTIR) was conducted using a Perkin Elmer spectrometer in $\mathrm{KBr}$ pellets. The composition and chemical state of the elements in the catalysts were measured using an Xray photoelectron spectrometer (XPS, VG ESCALAB 250) with Al $\mathrm{K} \alpha$ radiation $(h \nu=1486.8 \mathrm{eV})$. Ultraviolet-visible (UV-vis) absorption spectra were obtained on U-3310 spectrometer (Hitachi, Japan) in the wavelength range of 300 to $800 \mathrm{~nm}$. Photoluminescence (PL) spectroscopic investigations were carried out on a F-7000 fluorescence spectrophotometer (Hitachi, Japan) with an excitation wavelength at $273 \mathrm{~nm}$ using a $150 \mathrm{~W}$ Xe lamp as the excitation source. The BrunauerEmmett-Teller (BET) surface area was measured with an ASAP2010 analyzer. The photocurrent measurements were conducted on an electrochemical workstation in a standard threeelectrode system, using a platinum wire and the saturated $\mathrm{Ag} /$ $\mathrm{AgCl}$ electrode as the counter electrode and reference electrode, respectively. The working electrode was prepared by coating the catalysts on a $1.8 \mathrm{~cm} \times 1.2 \mathrm{~cm}$ fluorine-doped tin oxide (FTO) glass substrate. A $300 \mathrm{~W}$ Xe lamp with a $420 \mathrm{~nm}$ cutoff filter was used as a light source.

\subsection{Photodegradation of RhB}

The photocatalytic performance was examined by monitoring the degradation of Rhodamine $\mathrm{B}(\mathrm{RhB})$ in an aqueous solution at room temperature under visible light irradiation using a $300 \mathrm{~W}$ xenon lamp with $400 \mathrm{~nm}$ cutoff filters as light source. In each experiment, $10 \mathrm{mg}$ of photocatalyst was dispersed in $50 \mathrm{~mL}$ $\mathrm{RhB}$ aqueous solution with an initial concentration of $10 \mathrm{mg}$ $1^{-1}$. Prior to irradiation, the suspension was magnetically stirred in the dark room for $60 \mathrm{~min}$ to reach sorption equilibrium. During the photocatalysis process, $1 \mathrm{ml}$ of the sample was withdrawn from the reaction cell at 10 min intervals and then centrifuged for measuring the characteristic UV-vis absorption of RhB. The absorption peak maximum was employed in evaluating the concentration of $\mathrm{RhB}$. The degradation rate of $\mathrm{RhB}$ can be calculated accordingly:

$$
\text { Degradation rate }=\left(C_{0}-C_{t}\right) / C_{0}
$$

where $C_{0}$ is the sorption equilibrium concentration of $\mathrm{RhB}$ and $C_{t}$ is the concentration of RhB at reaction time $t$.

\section{Results and discussion}

The morphologies of the representative samples are shown in SEM micrographs. Fig. 1(a) indicates that the pure g- $\mathrm{C}_{3} \mathrm{~N}_{4}$ has a layered structure with some crinkled flakes. These $\mathrm{g}-\mathrm{C}_{3} \mathrm{~N}_{4}$ layers heaped together to form irregular particles. The Fe(II) and $\mathrm{S}$ codoped g- $\mathrm{C}_{3} \mathrm{~N}_{4}$ sheets in Fig. 1(b) become the lamella structures curved even more than that of the Fe(II) doped g- $\mathrm{C}_{3} \mathrm{~N}_{4}$ (Fig. 1(c)) with more irregular porous structures. The mesoporous structures may be caused by the decomposition of TCA during polymerization process, while the crimped structures are arisen from the larger radii of doped $\mathrm{Fe}(\mathrm{II})$ and $\mathrm{S}$ than those of the host $\mathrm{C}$ and $\mathrm{N}$ atoms. ${ }^{25}$ The $\mathrm{Fe}(\mathrm{II})+\mathrm{S}$ codoped $\mathrm{g}-\mathrm{C}_{3} \mathrm{~N}_{4}$ has a large number of mesopores, which demonstrates a higher specific surface area, possibly leading to easy transportation of pollutant to the interior surface via the interconnected mesopores. The energy dispersive $\mathrm{X}$-ray (EDX) analysis shows that the composition of the $\mathrm{Fe}(\mathrm{II})-\mathrm{S}$ codoped $\mathrm{g}-\mathrm{C}_{3} \mathrm{~N}_{4}$ comprising rich carbon $(\mathrm{C})$ and nitrogen $(\mathrm{N})$ with dispersed $\mathrm{Fe}$ and $\mathrm{S}$ elements. The overlapped C, N, Fe and S element EDS image (Fig. 1(d)) suggests that the $\mathrm{Fe}(\mathrm{II})$ and $\mathrm{S}$ elements are dispersed in $\mathrm{g}-\mathrm{C}_{3} \mathrm{~N}_{4}$ sheets. The EDX elemental mappings in Fig. $1(\mathrm{e}-\mathrm{h})$ clearly show that the Fe and $\mathrm{S}$ elements are distributed homogeneously on the continuous $\mathrm{C}, \mathrm{N}$ elemental background.

The crystal structures of the pure, the Fe(II)-doped and the $\mathrm{Fe}(\mathrm{II})-\mathrm{S}$ codoped $\mathrm{g}-\mathrm{C}_{3} \mathrm{~N}_{4}$ are demonstrated by their XRD patterns in Fig. 2. For the pure g- $\mathrm{C}_{3} \mathrm{~N}_{4}$, XRD pattern displays two distinct diffraction peaks located at $2 \theta$ of about $13.1^{\circ}$ and $27.3^{\circ}$, which are in good accordance with the characteristic (100) and (002) planes of $\mathrm{g}-\mathrm{C}_{3} \mathrm{~N}_{4} \cdot{ }^{24}$ The peak for (100) plane corresponds to the repeating in-plane structural packing motif of the tri-s-triazine unit with a period of $0.67 \mathrm{~nm}$, which is slightly smaller than the 


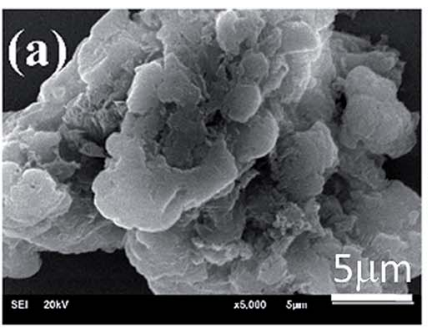

C K $\alpha 12$
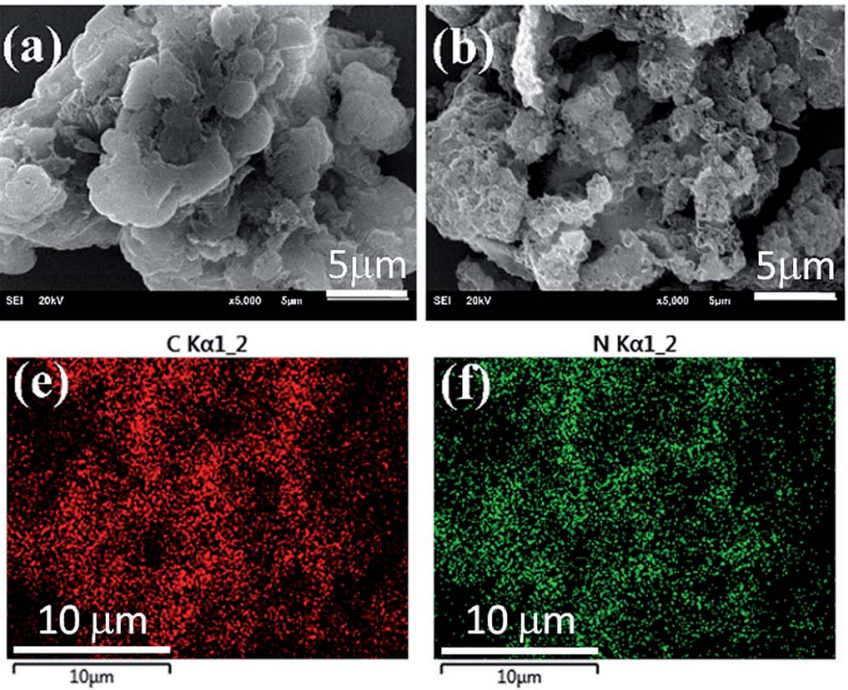

N K $\alpha 1 \_2$
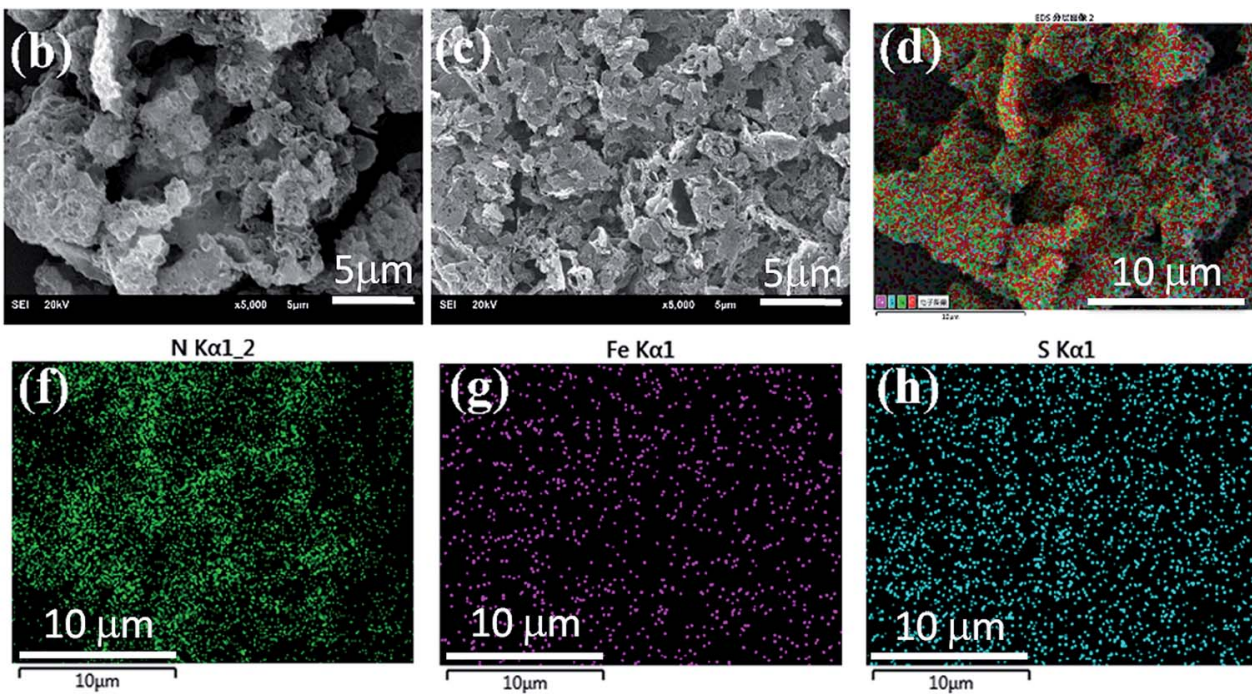

$\mathrm{Fe} \mathrm{K} \alpha 1$
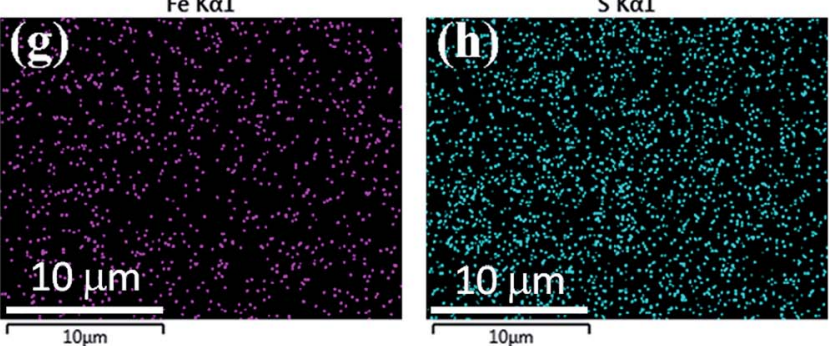

Fig. 1 SEM images of (a) the pure, (b) Fe(॥)/S and (c) Fe(॥) doped g- $\mathrm{C}_{3} \mathrm{~N}_{4}$ photocatalysts. Elemental EDX overlapped images of $\mathrm{C}, \mathrm{N}$, Fe and $\mathrm{S}$ (d) and mappings for $\mathrm{C}(\mathrm{e}), \mathrm{N}(\mathrm{f}), \mathrm{Fe}(\mathrm{g})$ and $\mathrm{S}(\mathrm{h})$ for the $\mathrm{Fe}(\|) / \mathrm{S}$ codoped $\mathrm{g}-\mathrm{C}_{3} \mathrm{~N}_{4}$.

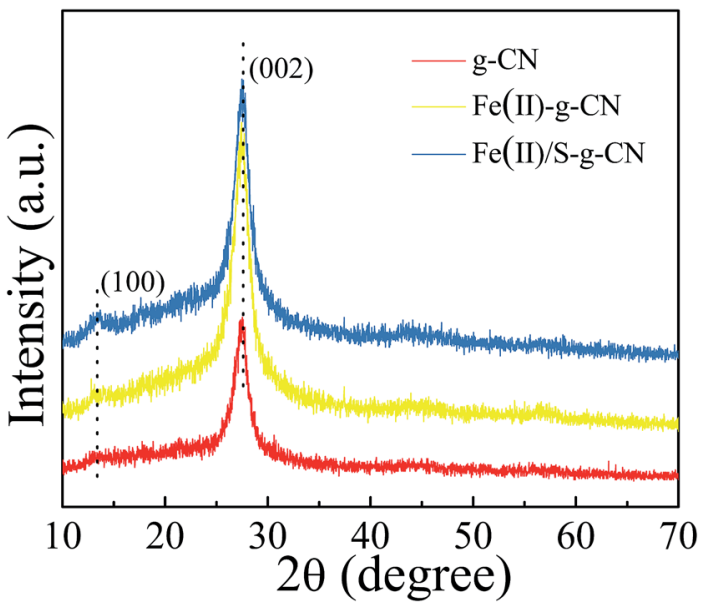

Fig. 2 XRD patterns of the $\mathrm{g}-\mathrm{C}_{3} \mathrm{~N}_{4}$, Fe(॥) doped and Fe(॥)/S codoped of $\mathrm{g}-\mathrm{C}_{3} \mathrm{~N}_{4}$ catalysts.

theoretical value of $0.73 \mathrm{~nm}$. The smaller in-plane packing motif suggests that the structure of $\mathrm{g}-\mathrm{C}_{3} \mathrm{~N}_{4}$ layer is corrugated slightly after polymerization of melamine. The peak for (002) crystal plane of $\mathrm{g}-\mathrm{C}_{3} \mathrm{~N}_{4}$ is attributed to the lattice planes formed by stacking the conjugated aromatic systems into layered structure with an interlayer distance of $0.33 \mathrm{~nm}$. This illustrates that the $\mathrm{g}^{-} \mathrm{C}_{3} \mathrm{~N}_{4}$ has a layered structure similar to graphite. Upon Fe(II) and S doping, the positions of these two peaks do not change. This result indicates that the $\mathrm{Fe}(\mathrm{II})$ and $\mathrm{S}$ atoms are incorporated in the $\mathrm{g}_{-} \mathrm{C}_{3} \mathrm{~N}_{4}$ layer, and light doping of $\mathrm{Fe}(\mathrm{II})$ and $\mathrm{S}$ has no significant effect on the crystal structure of $\mathrm{g}-\mathrm{C}_{3} \mathrm{~N}_{4}$. The intensities of the diffraction peaks increase after $\mathrm{Fe}(\mathrm{II})$ and $\mathrm{S}$ doing, indicating a better crystallinity than that of the pure g- $\mathrm{C}_{3} \mathrm{~N}_{4}$.

The FTIR spectra of the pure, the Fe(II)-doped and the Fe(II)-S codoped $\mathrm{g}-\mathrm{C}_{3} \mathrm{~N}_{4}$ catalysts are depicted in Fig. 3, in which the typical characteristic peaks at 1312, 1390, 1534, and $1625 \mathrm{~cm}^{-1}$ can be assigned to the stretching modes of the aromatic C- $\mathrm{N}$

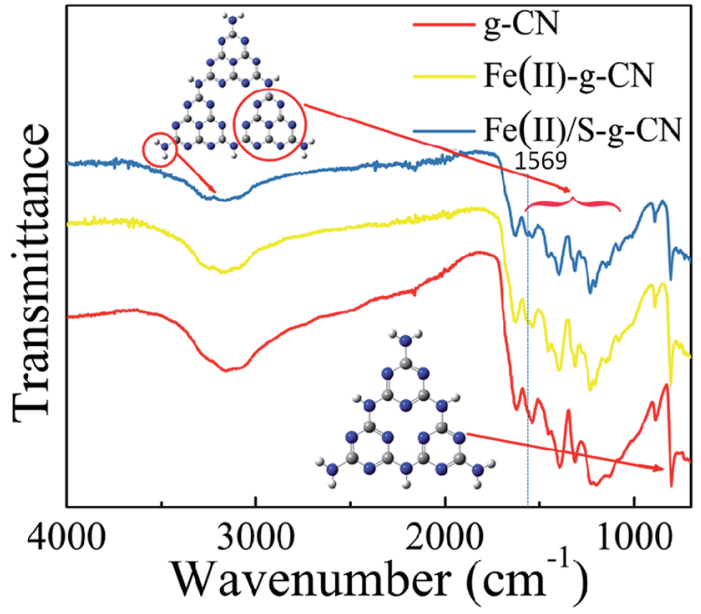

Fig. 3 FT-IR spectra of the pure, Fe(॥) doped and Fe(॥)/S codoped of $\mathrm{g}-\mathrm{C}_{3} \mathrm{~N}_{4}$.

heterocycle and peak at $805 \mathrm{~cm}^{-1}$ is ascribed to the breathing mode of the triazine units. ${ }^{25-28}$ The peak at $1228 \mathrm{~cm}^{-1}$ represents the stretching vibration of $\mathrm{C}-\mathrm{NH}-\mathrm{C}$ bridges. ${ }^{28}$ This demonstrates that the original graphitic $\mathrm{C}-\mathrm{N}$ network in the structure of $\mathrm{g}-\mathrm{C}_{3} \mathrm{~N}_{4}$ is kept intact upon doping. The broad peaks at $3000-3400 \mathrm{~cm}^{-1}$ are ascribed to the stretching modes of $\mathrm{N}-\mathrm{H}$, indicating there exist $\mathrm{N}-\mathrm{H}$ bonds at the edge of the polymerized triazine. Compared to the pure g- $\mathrm{C}_{3} \mathrm{~N}_{4}$, a new peak at $1569 \mathrm{~cm}^{-1}$ appears in FTIR spectra for the $\mathrm{Fe}(\mathrm{II})-\mathrm{S}$ codoped $\mathrm{g}-\mathrm{C}_{3} \mathrm{~N}_{4}$, which can be attributed to the stretching mode of $\mathrm{Fe}-\mathrm{N}$ bond in the coordination complex, confirming that the Fe ion coordinates at the pore site of $\mathrm{g}-\mathrm{C}_{3} \mathrm{~N}_{4}$ lattice.$^{26}$ It is noteworthy that the FTIR spectrum does not change dramatically after Fe(II) doping, which may show that the Fe(II) ion has little interaction with the aromatic $\mathrm{C}-\mathrm{N}$ rings.

Fig. 4 shows the high resolution XPS spectra of C, N, Fe and S elements in the pure g- $\mathrm{C}_{3} \mathrm{~N}_{4}, \mathrm{Fe}(\mathrm{II})$-doped, and $\mathrm{Fe}(\mathrm{II})-\mathrm{S}$ codoped 

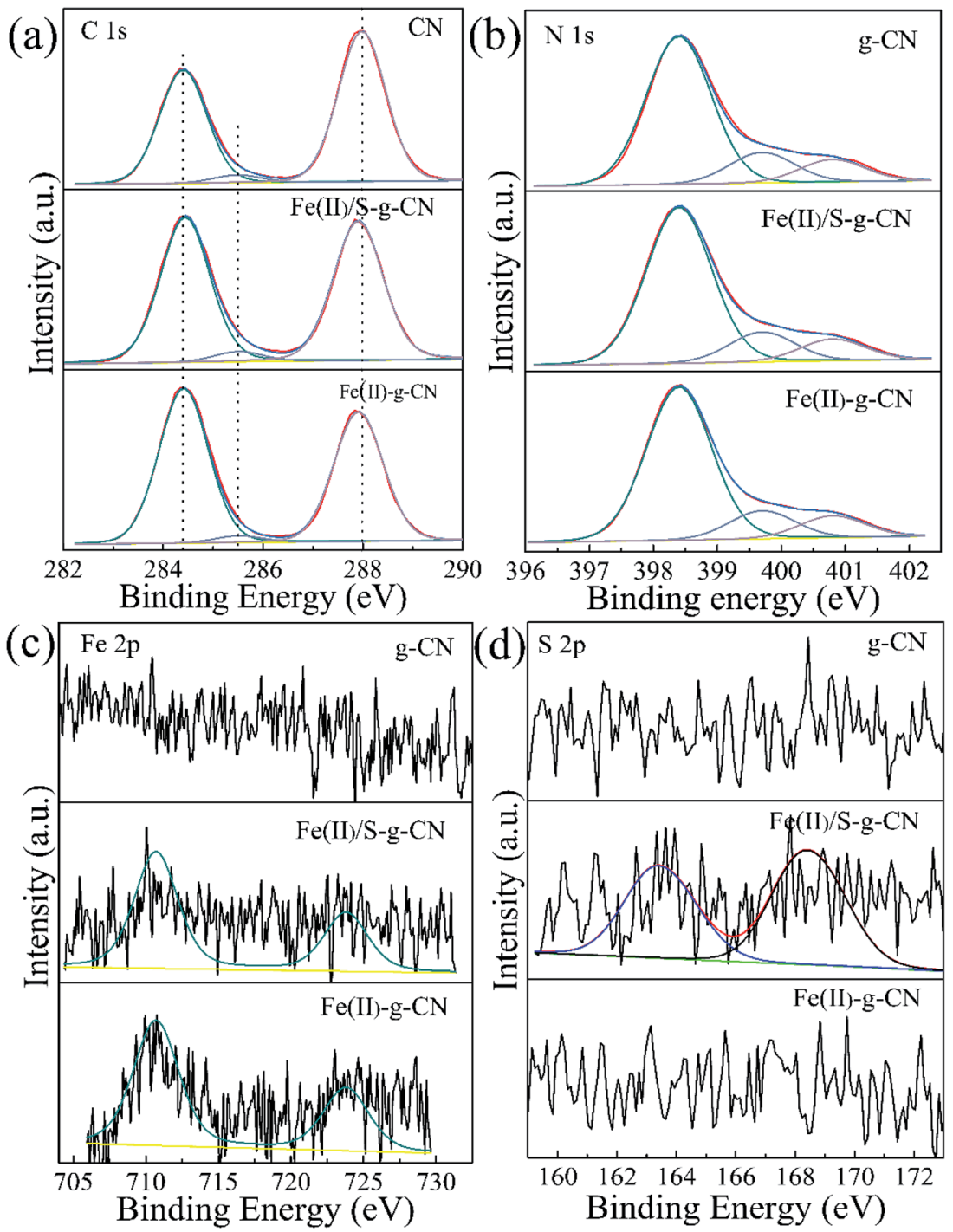

Fig. 4 XPS high resolution spectra for $\mathrm{C} 1 \mathrm{~s}(\mathrm{a})$ and $\mathrm{N} 1 \mathrm{~s}(\mathrm{~b})$, Fe $2 \mathrm{p}(\mathrm{c})$ and $\mathrm{S} 2 \mathrm{p}$ (d) of the pure $\mathrm{g}-\mathrm{C}_{3} \mathrm{~N}_{4}$ nanosheets $(\mathrm{g}-\mathrm{CN})$ and Fe(॥) doped g- $\mathrm{C}_{3} \mathrm{~N}_{4}$ $(\mathrm{Fe}(॥)-\mathrm{g}-\mathrm{CN})$ and $\mathrm{Fe}(॥)+\mathrm{S}$ codoped $\mathrm{g}-\mathrm{C}_{3} \mathrm{~N}_{4}(\mathrm{Fe}(॥) / \mathrm{S}-\mathrm{g}-\mathrm{CN})$.

$\mathrm{g}^{-} \mathrm{C}_{3} \mathrm{~N}_{4}$. The $\mathrm{C}$ 1s spectra of all three samples are shown in Fig. 4(a). For the pure g- $\mathrm{C}_{3} \mathrm{~N}_{4}$ nanosheets, the peaks centered at about $287.98 \mathrm{eV}$ (C1) is typically attributed to the $\mathrm{sp}^{2}$ hybrid C atoms bonded to $\mathrm{N}$-containing aromatic skeleton rings $(\mathrm{N}-\mathrm{C}=$ $\mathrm{N})$. The peak at $285.48 \mathrm{eV}(\mathrm{C} 2)$ is related to the $\mathrm{C}-\mathrm{NH}_{2}$ bonded in the triazine ring of the reactant intermediary product. ${ }^{10,18}$ The peak at $284.40 \mathrm{eV}$ (C3) could be attributed to the graphitic carbon $(\mathrm{C}-\mathrm{C}$ and $\mathrm{C}=\mathrm{C}){ }^{28}$ The binding energy of $\mathrm{C} 1$ shifts to a lower value of $287.90 \mathrm{eV}$ after ferrous ion doping. This may be caused by the formation of $\mathrm{Fe}-\mathrm{N}$ coordination bond leading to the partial breakage of the aromatic $\pi$ bond to $\mathrm{N}-\mathrm{C}-\mathrm{N}$, coexisting of $\mathrm{N}-\mathrm{C}-\mathrm{N}$ and $\mathrm{N}-\mathrm{C}=\mathrm{N} .{ }^{26}$ The $\mathrm{N} 1 \mathrm{~s}$ spectra for the pure g$\mathrm{C}_{3} \mathrm{~N}_{4}$, and the $\mathrm{Fe}$ (II)-doped, $\mathrm{Fe}$ (II)-S codoped g- $\mathrm{C}_{3} \mathrm{~N}_{4}$ in Fig. 4(b) can be decomposed into three typical peaks located at about $398.40 \mathrm{eV}(\mathrm{N} 1), 399.70 \mathrm{eV}(\mathrm{N} 2), 400.80 \mathrm{eV}$ (N3), which could be attributed to the $\mathrm{sp}^{2}$-hybridized aromatic $\mathrm{N}$ atoms bonded to carbon atoms $(\mathrm{C}-\mathrm{N}=\mathrm{C})$, and $\mathrm{sp}^{3}$-hybridized $\mathrm{N}$ atoms of $\mathrm{N}(-\mathrm{C})_{3}$ and terminal amino functions $\left(\mathrm{C}-\mathrm{NH}_{2}\right)$, respectively. ${ }^{29-33}$ The $\mathrm{S}$ atomic dopant does not change the binding energy of C 1s spectrum since the element $\mathrm{S}$ has a similar electronegativity as the $\mathrm{C}$ atom.

The Fe 2p spectra for the Fe(II)-doped, Fe(II)-S codoped g$\mathrm{C}_{3} \mathrm{~N}_{4}$ in Fig. 4(c) show the peaks at $710.7 \mathrm{eV}$ and $723.8 \mathrm{eV}$ are ascribed to the splitting orbits of Fe $2 \mathrm{p}_{3 / 2}$ and $2 \mathrm{p}_{1 / 2}$, consistent with reported $\mathrm{Fe}^{2+}$ binding energies. ${ }^{26}$ This observation demonstrates that $\mathrm{Fe}(\mathrm{II})$ ion forms coordination bond with the edge $\mathrm{N}$ atoms of hepazine. ${ }^{31,33}$ The $\mathrm{Fe}(\mathrm{II})$ atom is imbedded in the pore centre among three tri-s-triazine units of $g-\mathrm{C}_{3} \mathrm{~N}_{4}$ in the oxidation state of $\mathrm{Fe}(\mathrm{II})$ ion by forming $\mathrm{Fe}(\mathrm{II})-\mathrm{N}$ bonds. ${ }^{22-24,33} \mathrm{As}$ for the $\mathrm{Fe}(\mathrm{II})-\mathrm{S}$ codoped $\mathrm{g}-\mathrm{C}_{3} \mathrm{~N}_{4}$, a S 2 p peak located at $163.1 \mathrm{eV}$ can be reasonably assigned to C-S bonds formed in $\mathrm{g}-\mathrm{C}_{3} \mathrm{~N}_{4}$ lattice via substituting $\mathrm{N}^{34,35}$ The peak at $168.0 \mathrm{eV}$ is ascribed to $\mathrm{S}=\mathrm{O}$ in the intermediate product of sulfoxide resulting from the decomposition of TCA. ${ }^{20}$ By removing the adventitious carbon contamination, the $\mathrm{C} / \mathrm{N}$ atomic ratio is 0.76 for the pure $\mathrm{g}^{-} \mathrm{C}_{3} \mathrm{~N}_{4}$, which is fairly close to the stoichiometric value of $\mathrm{g}$ - 
$\mathrm{C}_{3} \mathrm{~N}_{4}$. The $\mathrm{C} / \mathrm{N}$ atomic ratio for the $\mathrm{Fe}(\mathrm{II}), \mathrm{S}$ codoped $\mathrm{g}-\mathrm{C}_{3} \mathrm{~N}_{4}$ is about 0.81 , which is slightly larger than that of the pure $g-\mathrm{C}_{3} \mathrm{~N}_{4}$. XPS results showed that the $\mathrm{Fe}(\mathrm{II})$ and $\mathrm{S}$ atoms are doped into $\mathrm{g}$ $\mathrm{C}_{3} \mathrm{~N}_{4}$ lattice and may preferentially substitute $\mathrm{N}$ atoms. For the $\mathrm{Fe}(\mathrm{II})-\mathrm{S}$ codoped $\mathrm{g}-\mathrm{C}_{3} \mathrm{~N}_{4}$, the $\mathrm{S}$ content of atomic percentage is about $0.09 \%$ and the Fe(II) is about $0.20 \%$. Taken XPS and XRD results into consideration, $\mathrm{Fe}(\mathrm{II})$ ions are suggested to position in the pore centre among three tri-s-triazine units by forming $\mathrm{Fe}(\mathrm{II})-\mathrm{N}$ bonds with the lone-pair $\mathrm{sp}^{2}$ electrons of $\mathrm{N}$ atoms.

The UV-vis diffuses absorbance spectra of the pure, $\mathrm{Fe}(\mathrm{II})$ doped and $\mathrm{Fe}(\mathrm{II})-\mathrm{S}$ codoped $\mathrm{g}-\mathrm{C}_{3} \mathrm{~N}_{4}$ are shown in Fig. 5(a). There is a sharp absorption edge for the pure $\mathrm{g}-\mathrm{C}_{3} \mathrm{~N}_{4}$ nanosheets at around $460 \mathrm{~nm}$ indexing to the bandgap energy of about $2.7 \mathrm{eV}$, which is associated with the photocatalytic property in visible light. ${ }^{4,24}$ It shows enhanced visible light absorption intensity and the red shift edge via Fe(II) and S doping. The KubelkaMunk plots in Fig. 4(b) show that the adsorption edge is red shifted with lower bonding energy of $2.51 \mathrm{eV}$ for the $\mathrm{Fe}$ (II) and $\mathrm{Fe}(\mathrm{II})-\mathrm{S}$ codoped $\mathrm{g}-\mathrm{C}_{3} \mathrm{~N}_{4}$. The absorption intensity is remarkably enhanced in the visible region after the Fe(II) and $\mathrm{S}$ doping. ${ }^{29}$ SEM images show that $\mathrm{Fe}(\mathrm{II})$ and $\mathrm{S}$ doping causes the $\mathrm{g}-\mathrm{C}_{3} \mathrm{~N}_{4}$ sheets curling up (Fig. 1(b)). The crimped structure facilitates the $\mathrm{n}-\pi *$ transitions. These results reveal that the $\mathrm{Fe}(\mathrm{II})-\mathrm{S}$ doped g- $\mathrm{C}_{3} \mathrm{~N}_{4}$ composites could significantly promote the optical absorption performance and enhance the utilization efficiency of solar light, which subsequently results in a higher photocatalytic activity. ${ }^{28}$

The photoluminescence (PL) studies were carried out to investigate the recombination/separation of photoinduced charge carriers in the pure, $\mathrm{Fe}(\mathrm{II})$ doped and Fe(II)-S codoped g-
$\mathrm{C}_{3} \mathrm{~N}_{4}$ under the excitation wavelength of $274 \mathrm{~nm}$. The measured PL spectra, as shown in Fig. 5(c), show that all of the samples exhibit a main emission peak appearing at about $440 \mathrm{~nm}$, which is consistent with the reported value in the literature. ${ }^{34,35}$ Compared to the pure $\mathrm{g}-\mathrm{C}_{3} \mathrm{~N}_{4}$, the $\mathrm{Fe}(\mathrm{II})$ doped and the $\mathrm{Fe}(\mathrm{II})-\mathrm{S}$ doped $\mathrm{g}-\mathrm{C}_{3} \mathrm{~N}_{4}$ give weaker $\mathrm{PL}$ intensities revealing the lower recombination probability of photoinduced electrons and holes, which could give rise to a higher photocatalytic activity.

The $\mathrm{Fe}(\mathrm{II})$ and $\mathrm{S}$ codoped $\mathrm{g}-\mathrm{C}_{3} \mathrm{~N}_{4}$ exhibits a largest specific surface area among these three samples, showed in Fig. 5(d). The specific surface area is $13.40 \mathrm{~m}^{2} \mathrm{~g}^{-1}, 57.28 \mathrm{~m}^{2} \mathrm{~g}^{-1}$, and $59.37 \mathrm{~m}^{2} \mathrm{~g}^{-1}$, and the pore area is $15.48 \mathrm{~m}^{2} \mathrm{~g}^{-1}, 53.53 \mathrm{~m}^{2} \mathrm{~g}^{-1}$, and $75.84 \mathrm{~m}^{2} \mathrm{~g}^{-1}$ for the pure, $\mathrm{Fe}$ (II) doped, and $\mathrm{Fe}(\mathrm{II})+\mathrm{S}$ doped g- $\mathrm{C}_{3} \mathrm{~N}_{4}$ catalysts, respectively. Fig. 5(d) indicates that the apparent curves follow the type IV adsorption-desorption isotherm with $\mathrm{N}_{2}$ hysteresis loop, which is mainly arisen from the massive presence of mesopores. Therefore, $\mathrm{Fe}(\mathrm{II})+\mathrm{S}$ codoped photocatalyst will provide more active sites, facilitating photocatalytic activity. ${ }^{36,37}$

The electrochemical impedance spectra (EIS) of the pure g$\mathrm{C}_{3} \mathrm{~N}_{4}$ and the $\mathrm{g}-\mathrm{C}_{3} \mathrm{~N}_{4}$ doped with $\mathrm{Fe}(\mathrm{II})$ and $\mathrm{S}$ were measured to understand the photocatalytic mechanism. The arc on the EIS Nyquist plot indicates the charge transfer resistance. Generally speaking, the smaller arc radius implies a lower charge transfer resistance. ${ }^{21,24}$ As shown in Fig. 6(a), the Nyquist plots of all the $\mathrm{Fe}(\mathrm{II})$ and $\mathrm{S}$ doped $\mathrm{g}-\mathrm{C}_{3} \mathrm{~N}_{4}$ samples give a smaller arc radius attributing to the reduced electric resistance and enhanced conductivity by doping with $\mathrm{Fe}$ (II) and S elements compared to the pure $\mathrm{g}-\mathrm{C}_{3} \mathrm{~N}_{4}$. In fact, the arc radius for $\mathrm{Fe}(\mathrm{II})-\mathrm{S}$ codoped $\mathrm{g}$ $\mathrm{C}_{3} \mathrm{~N}_{4}$ is smallest in all three samples, which is associated with
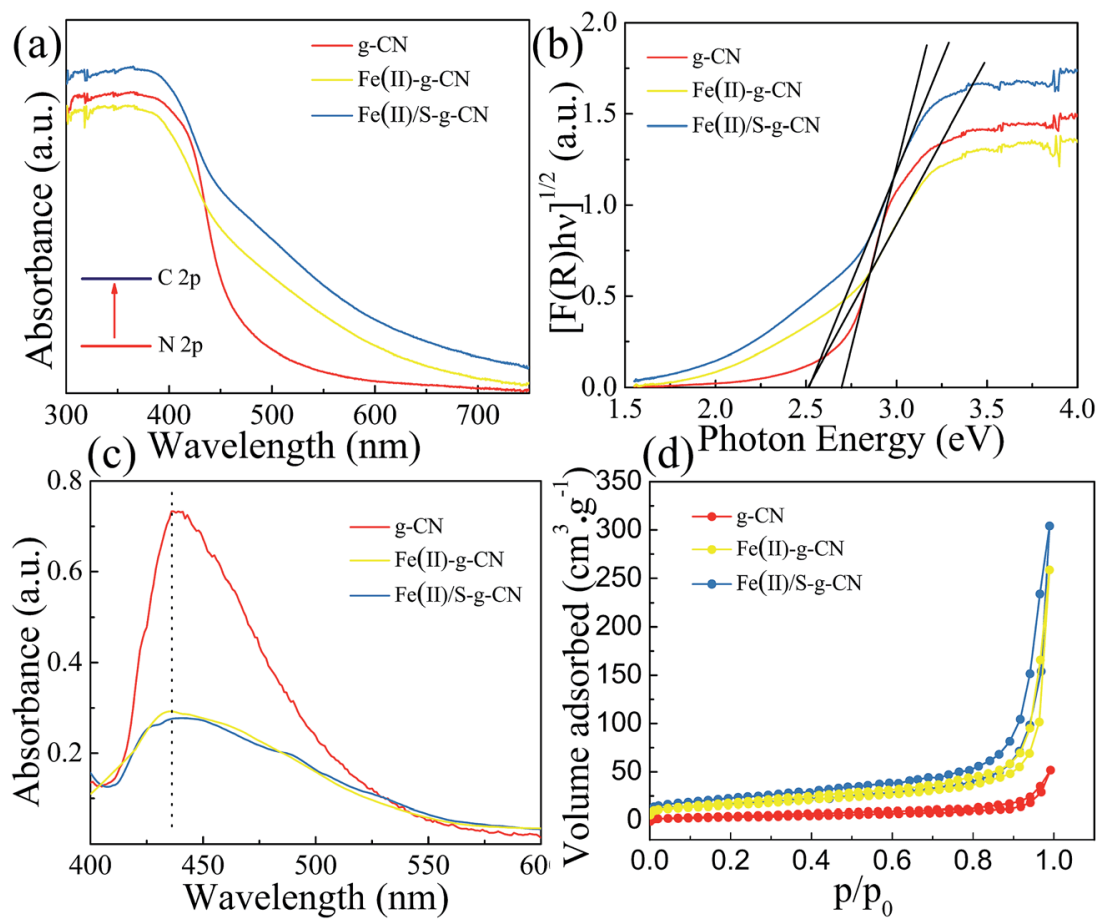

Fig. 5 UV-vis absorbance spectra (a), corresponding Kubelka-Munk plots (b), PL (c) and adsorption-desorption isothermal curve of $\mathrm{N}_{2}$ (d) of the pure $\mathrm{g}-\mathrm{C}_{3} \mathrm{~N}_{4}$ nanosheets and Fe(॥) $-\mathrm{g}-\mathrm{C}_{3} \mathrm{~N}_{4}$ and $\mathrm{Fe}(\|) / \mathrm{S}-\mathrm{g}-\mathrm{C}_{3} \mathrm{~N}_{4}$. 

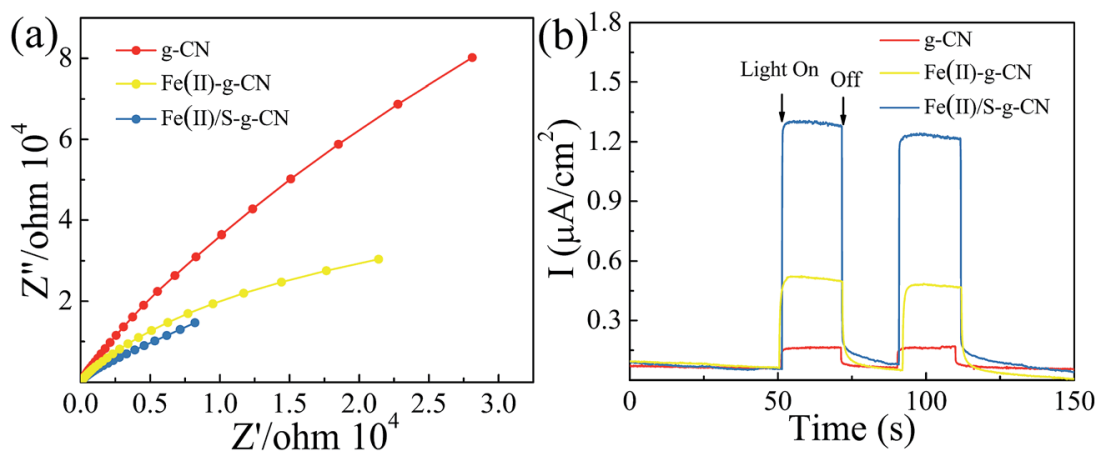

Fig. 6 EIS spectra (a), transient photocurrent response (b) of the pure, $\mathrm{Fe}(\Perp)-\mathrm{g}-\mathrm{C}_{3} \mathrm{~N}_{4}$ and $\mathrm{Fe}(\Perp) / \mathrm{S}-\mathrm{g}-\mathrm{C}_{3} \mathrm{~N}_{4}$ catalysts.

the highest efficiency of the charge separation. ${ }^{38-41}$ Moreover, this changing trend in the arc radius for $\mathrm{g}-\mathrm{C}_{3} \mathrm{~N}_{4}$ samples is consistent with the results displayed in PL spectra.

The transient photocurrent responses of all samples were recorded in Fig. 6(b). The photocurrent shows a fast response to light irradiation with a good reproducibility for each on-off cycle. That showed a rapid and steady photocurrent response with reproducibility for each on-off cycle. The current density for $\mathrm{Fe}(\mathrm{II})-\mathrm{S}$ codoped $\mathrm{g}-\mathrm{C}_{3} \mathrm{~N}_{4}$ is about 12 times of that observed for pure sample, revealing the most effective separation and transition of photoinduced electron/hole pairs, which is consistent with PL spectra.

The photocatalytic performances of the pure, Fe(II) doped and $\mathrm{Fe}(\mathrm{II})-\mathrm{S}$ doped $\mathrm{g}-\mathrm{C}_{3} \mathrm{~N}_{4}$ were evaluated by $\mathrm{RhB}$ degradation under visible light irradiation $(\lambda>420 \mathrm{~nm})$, as shown in Fig. 7(a). After 60 min irradiation with visible light, about $83.5 \%$ of $\mathrm{RhB}$ is degraded in presence of the Fe(II) doped g- $\mathrm{C}_{3} \mathrm{~N}_{4}$, compared to that of only $33.3 \%$ of $\mathrm{RhB}$ decomposition with the pure g- $\mathrm{C}_{3} \mathrm{~N}_{4}$. As for the $\mathrm{Fe}(\mathrm{II})-\mathrm{S}$ codoped g- $\mathrm{C}_{3} \mathrm{~N}_{4}$, approximately $91 \%$ of $\mathrm{RhB}$ is decomposed after $60 \mathrm{~min}$ with visible light irradiation. There is almost no self-degradation of $\mathrm{RhB}$ under visible light irradiation in our experiments. The photodegradation of RhB follows the first order dynamics equation:

$$
-\ln \left(C_{0} / C_{t}\right)=k t
$$

where $C_{0}, C_{t}, k$ and $t$ are the initial concentration, the concentration at time $t$, reaction coefficient and time $t$, respectively. The first order kinetics, illustrated in Fig. 7(b), shows that the degradation rates for the $\mathrm{Fe}$ and $\mathrm{Fe} / \mathrm{S}$ doped $\mathrm{g}-\mathrm{C}_{3} \mathrm{~N}_{4}$ are enhanced by 5.4 and 4.2 times compared with the pure material. The stability for the $\mathrm{Fe} / \mathrm{S}$ doped $\mathrm{g}-\mathrm{C}_{3} \mathrm{~N}_{4}$ is illustrated in Fig. 7(c). The photodegradation rate does not experience any significant changes after 4 cycles of degradation experiments.

In order to further explain the photocatalytic mechanism of the degradation $\mathrm{RhB}$ under visible light, benzoquinone (BQ, $\left.1.5 \mathrm{ml}, 0.1 \mathrm{mM} \mathrm{l}^{-1}\right)$, tert-butyl alcohol $(t-\mathrm{BuOH}, 1.5 \mathrm{ml})$ and methanol (MeOH, $1.5 \mathrm{ml})$ were added into our model photocatalysis system to trap radical superoxide $\left({ }^{\circ} \mathrm{O}_{2}{ }^{-}\right)$, hydroxyl radicals ( $\left.{ }^{\circ} \mathrm{OH}\right)$ and hole $\left(\mathrm{h}^{+}\right),{ }^{41,42}$ respectively. The degradation rate did not change obviously by adding $t-\mathrm{BuOH}$ and $\mathrm{MeOH}$ in the photocatalytic process, as shown in Fig. 8, indicating hydroxyl radicals and holes are not the reactants for degradating RhB. While the degradation rate decreases dramatically upon adding a small amount of BQ, which clearly indicates that radical superoxide is the primary reactant in the $\mathrm{RhB}$ degradation process. The redox potentials for $\mathrm{OH} / \mathrm{OH}^{-}$and $\mathrm{O}_{2} / \mathrm{O}_{2}{ }^{-}$ were determined to be $+1.99 \mathrm{~V}$ and $-0.33 \mathrm{~V},{ }^{43,44}$ respectively. Theoretically, the conduction band and valence band of g- $\mathrm{C}_{3} \mathrm{~N}_{4}$ were $-1.22 \mathrm{~V}$ and $+1.57 \mathrm{~V}^{31,32}$ The conduction band of $\mathrm{g}-\mathrm{C}_{3} \mathrm{~N}_{4}$ is more negative than the redox potential of $\mathrm{O}_{2} /{ }^{\circ} \mathrm{O}_{2}{ }^{-}$, thus $\mathrm{O}_{2}$ can be reduced to $\mathrm{O}_{2}{ }^{-}$. The valence band of $\mathrm{g}^{-} \mathrm{C}_{3} \mathrm{~N}_{4}$ is less positive enough to oxide $\mathrm{OH}^{-}$to ${ }^{\circ} \mathrm{OH}$. These results suggest that $\mathrm{O}_{2}{ }^{-}$ takes part in the photocatalytic process, consistent with our experiment.

In order to get deeper insight into its catalytic mechanism and electronic structure, DFT calculations based on the Gaussian 09 software package were performed to model the $\mathrm{Fe}(\mathrm{II})$ and $\mathrm{S}$ doped $\mathrm{g}-\mathrm{C}_{3} \mathrm{~N}_{4}$ (001) layer with hexagonal honeycomb lattice structure containing three tri-s-triazine units. DFT B3LYP/6-31G(d) level of theory was used to optimize the geometry of g- $\mathrm{C}_{3} \mathrm{~N}_{4}$ with minimum energy as the initial structure. The highest occupied molecular orbital (HOMO) and the lowest unoccupied molecular orbital (LUMO), the surface electrostatic potential, and density of states were calculated based on B3LPY/Lanl2dz level for Fe(II), B3LPY/6-311g(d) level for C, N, S.

Fig. 9 shows the calculated HOMO, LUMO, and the surface electrostatic potential for the (001) lattice plane of $\mathrm{g}-\mathrm{C}_{3} \mathrm{~N}_{4}$ monolayer. The bigger the separation of HOMO and LUMO, the easier the separation of the photoinduced electron/hole and less the combination of charged carriers. For the pure $\mathrm{g}-\mathrm{C}_{3} \mathrm{~N}_{4}$ catalyst, the small separation of HOMO and LUMO, as shown in Fig. 9(a) may promote the photoinduced electron/hole recombination, leading to a lower photocatalytic activity. The migration of the photogenerated $\mathrm{e}^{-} / \mathrm{h}^{+}$pairs is not efficient due to the different localized HOMO and LUMO. HOMO suggests that the edge $\mathrm{N}$ atoms provide the oxidation sites for water to $\mathrm{O}_{2}$, whereas LUMO indicates that the edge $\mathrm{C}$ and the inner $\mathrm{N}$ atoms are the preferred reduction sites to form $\mathrm{H}_{2}{ }^{45,46}$ There are no HOMO and LUMO at the bridge $\mathrm{N}$ atoms inhibiting the carrier migration from one heptazine unit to another, reducing the photocatalytic performance. Fig. 9(b) shows the calculated molecular orbitals of $\mathrm{S}$ doped $\mathrm{g}-\mathrm{C}_{3} \mathrm{~N}_{4}$, which demonstrates that 

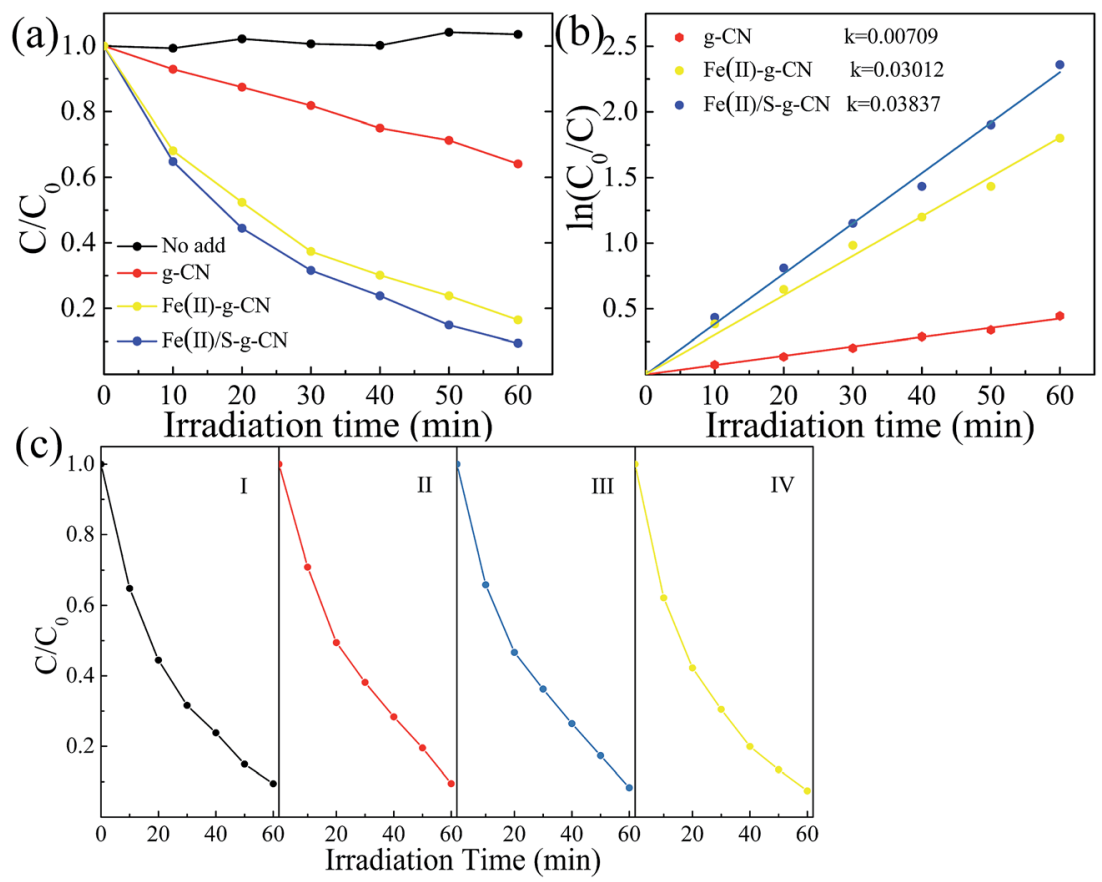

Fig. 7 Photocatalytic performances (a) and corresponding first-order reaction kinetics (b) in the degradation of RhB under visible light irradiation for the pure $g-C_{3} N_{4}$, the Fe(॥) $-g-C_{3} N_{4}$ and Fe(॥)/S $-g-C_{3} N_{4}$. Stability test of the Fe(॥)/S $-g-C_{3} N_{4}$ (c).
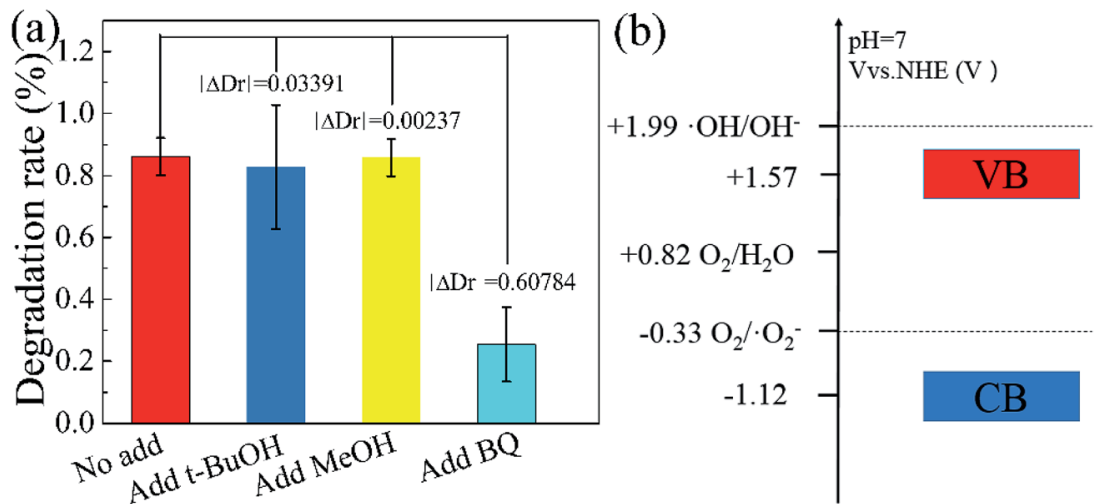

Fig. 8 Influence of various scavengers on the visible-light photocatalytic activity of $\mathrm{Fe}(\mathrm{II}) / \mathrm{S}-\mathrm{g}-\mathrm{C}_{3} \mathrm{~N}_{4}$ toward the degradation of RhB (a), electric potential diagram of $\mathrm{g}-\mathrm{C}_{3} \mathrm{~N}_{4}$ and related perssad (b).

the separation of HOMO and LUMO increases distinctly with the sulfur atom doping. The $\mathrm{S}$ atoms act as the reduction sites. The substitution of the edge $\mathrm{N}$ with $\mathrm{S}$ causes slightly stronger delocalized HOMO and LUMO compared to the pure $\mathrm{g}-\mathrm{C}_{3} \mathrm{~N}_{4}$ monolayer. The dispersion of the HOMO and LUMO distribution can enhance the carrier mobility. The substitution of the edge $\mathrm{N}$ with $\mathrm{S}$ causes stronger delocalized HOMO and LUMO, thus increases the reactive sites. Fig. 9(c) presents the calculated molecular orbitals of the Fe(II) doped $\mathrm{g}-\mathrm{C}_{3} \mathrm{~N}_{4}$. The separation of HOMO and LUMO increases after Fe(II) ion is imbedded in the pore centre among the three triazine units in the layered molecules. These results indicate that the separation of HOMO and LUMO increases with $\mathrm{Fe}$ (II) and S doping with S doping altering the electronic structure of triazine unit and $\mathrm{Fe}(\mathrm{II})$ doping enhancing the density of states of the pore among three triazine units. Our experimental study showed that ${ }^{\circ} \mathrm{O}_{2}{ }^{-}$is the main active species in the photodegradation of RhB. Thus, the surface electrostatic potential of the photocatalysts was calculated to investigate the separation of ${ }^{\circ} \mathrm{O}_{2}{ }^{-}$at the LUMO energy band from the catalyst surface, as shown at the bottom in Fig. 9. It is shown that the pore site has a negative potential, thus is the optimum site for ${ }^{\circ} \mathrm{O}_{2}{ }^{-}$separating from the surface of $\mathrm{g}-\mathrm{C}_{3} \mathrm{~N}_{4}$. The potentials deceases further with the Fe(II) and S doping, facilitating the separation of $\mathrm{O}_{2}{ }^{-}$and enhancing the photocatalytic activity.

The total and partial density of states (DOS) for the pure g$\mathrm{C}_{3} \mathrm{~N}_{4}$ is shown in Fig. 10(a). The DOS in valance band is mainly contributed by the nitrogen atoms, while the DOS in conduction 
(a)

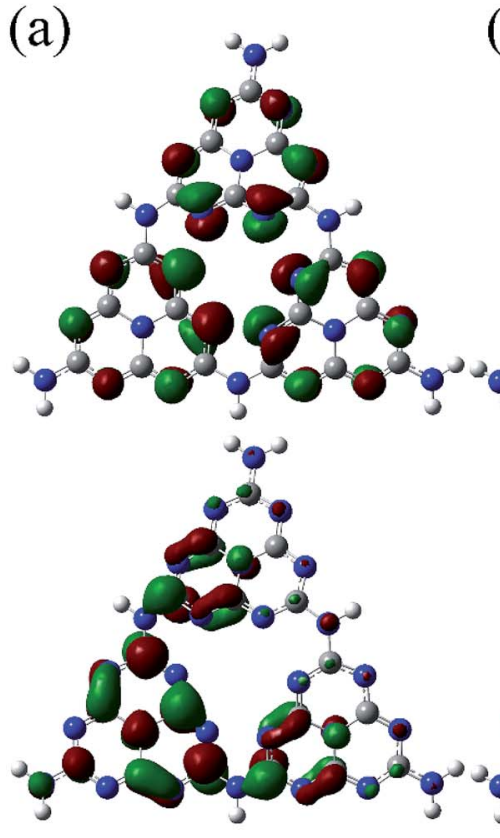

(b)

20
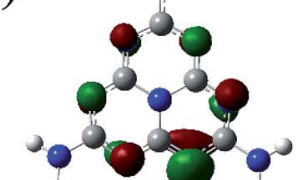

$\%$
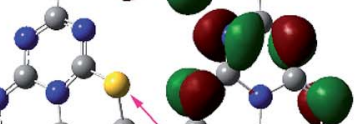

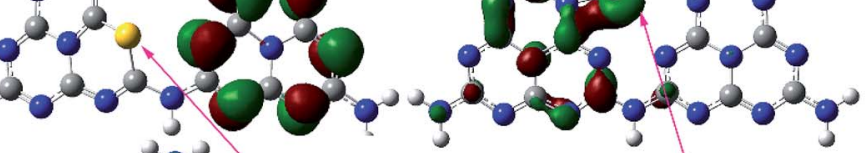
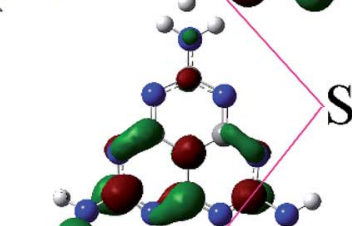

20

0. $\mathrm{Fe}(\mathrm{II})$
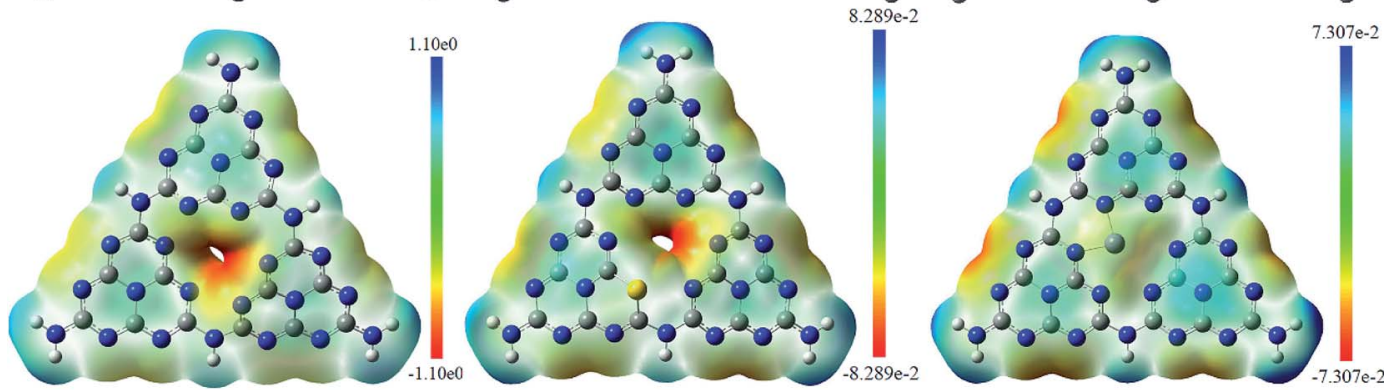

Fig. 9 Calculated HOMO (top), LUMO (middle) and surface electrostatic potential (bottom) of the pristine (a), S doped (b) and Fe(॥) doped (c) g$\mathrm{C}_{3} \mathrm{~N}_{4}$ monolayer. The isosurface is taken at a value of $0.003 \mathrm{e} \mathrm{bohr}^{-3}$. Carbon atoms are in grey and nitrogen in blue.
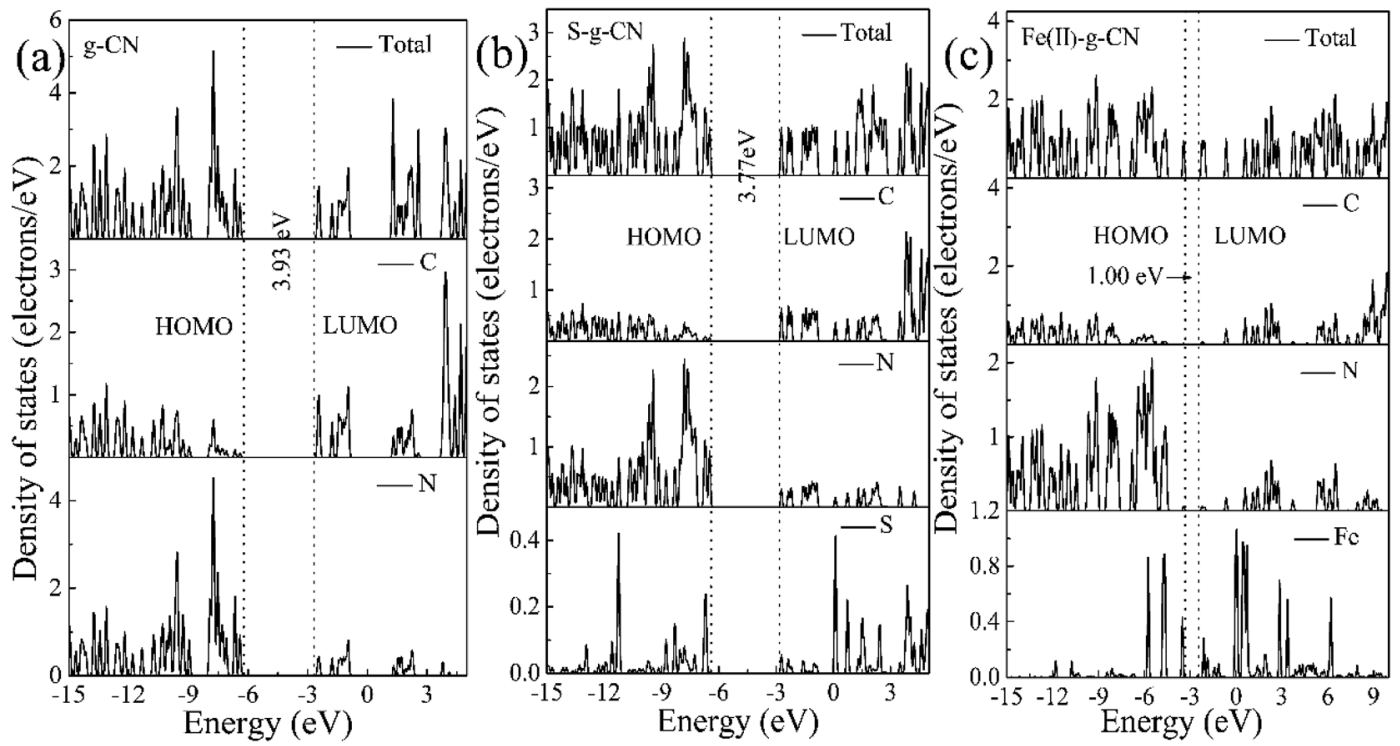

Fig. 10 Calculated total and partial DOS plots of C, N, S and Fe(॥) elements for the pristine (a), S doped (b) and (c) Fe(॥) doped g- $\mathrm{C}_{3} \mathrm{~N}_{4}$ monolayer. 


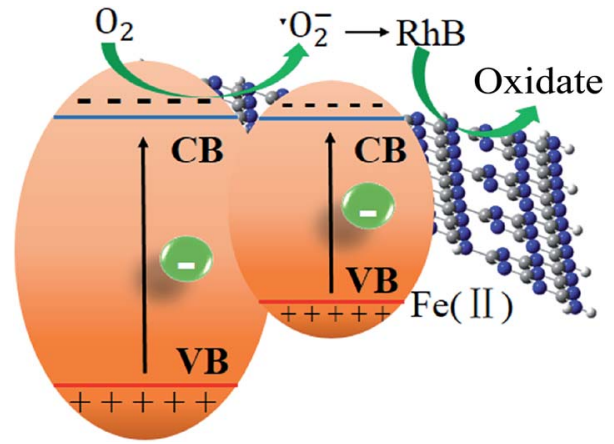

Scheme 1 Z-scheme photocatalytic systems.

band is from the carbon atoms. The bandgap is narrowing upon the $\mathrm{S}$ and $\mathrm{Fe}(\mathrm{II})$ doping and the Fermi level is shifted towards the conduction band, as shown in Fig. 10(b and c). The S doping changes the electronic structure of $\mathrm{g}-\mathrm{C}_{3} \mathrm{~N}_{4}$ by contributing to both valence and conduction bands. The bandgap between HOMO and LUMO is $3.77 \mathrm{eV}$ for the $\mathrm{S}$ doped $\mathrm{g}-\mathrm{C}_{3} \mathrm{~N}_{4}$. $\mathrm{Fe}$ (II) doping in the lattice of $g-\mathrm{C}_{3} \mathrm{~N}_{4}$ generates discrete energy level in the bandgap, thus deceasing the bandgap significantly to $1.0 \mathrm{eV}$ compared to the pure $\mathrm{g}-\mathrm{C}_{3} \mathrm{~N}_{4}$ with a bandgap of $3.93 \mathrm{eV}$. Therefore, our DFT calculation indicates that the nonmetal element $\mathrm{S}$ mainly changes the electronic structure of triazine unit, while the metal Fe(II) ion imbedded in the pore alters the energy band structure by exerting discrete energy level in the bandgap. ${ }^{4,48}$ The valence electron divergence between the dopant atoms and the adjacent intrinsic atoms yields new energy band in the $\mathrm{g}-\mathrm{C}_{3} \mathrm{~N}_{4}$ monolayer, thus changes its photocatalytic performance.

Finally, a tentative mechanism for photocatalytic degradation of RhB was proposed by taking above-mentioned experimental and theoretical strands into consideration. The photocatalytic mechanism of the degradation of $\mathrm{RhB}$ was illustrated in Scheme 1. S doping alters the electronic structure of triazine unit, while $\mathrm{Fe}$ ion forms a new impurity band above the valence band of the pure $\mathrm{g}-\mathrm{C}_{3} \mathrm{~N}_{4}$. This impurity band improves the separation of photoinduced electron/hole pairs. The photoinduced electrons jump more easily to the conduction band of $\mathrm{g}-\mathrm{C}_{3} \mathrm{~N}_{4}$ for the Fe impurity band locates above the valence band acting a bridge for electron transfer. The photoexcited electrons generated from $\mathrm{g}-\mathrm{C}_{3} \mathrm{~N}_{4}$ under visible-light irradiation would jump into the conduction band and combine with the dissolved $\mathrm{O}_{2}$ to form ${ }^{\circ} \mathrm{O}_{2}{ }^{-}$, with which $\mathrm{RhB}$ molecules were decomposed. The doping of $\mathrm{Fe}^{2+}$ significantly lowers the bandgap, enabling the harvest of major visible light and generating photoinduced electrons in the conduction band of $\mathrm{g}-\mathrm{C}_{3} \mathrm{~N}_{4}$, leading to a significant enhancement of the photocatalytic activity.

\section{Conclusion}

In summary, the $\mathrm{Fe}(\mathrm{II})$ and $\mathrm{S}$ codoped $\mathrm{g}-\mathrm{C}_{3} \mathrm{~N}_{4}$ photocatalyst was successfully prepared by a thermal condensation process of melamine, ferrous chloride and trithiocyanuric acid. Compared to the pure $\mathrm{g}-\mathrm{C}_{3} \mathrm{~N}_{4}$ nanosheets, the photocatalytic performance for $\mathrm{RhB}$ degradation is enhanced by a factor of 5.4 times for the $\mathrm{Fe}(\mathrm{II})-\mathrm{S}$ codoped $\mathrm{g}-\mathrm{C}_{3} \mathrm{~N}_{4}$, in which $\mathrm{Fe}(\mathrm{II})$ coordinates in the pore centre by forming $\mathrm{Fe}(\mathrm{II})-\mathrm{N}$ bonds and $\mathrm{S}$ atoms substitute the $\mathrm{N}$ atoms in the triazine unit. The stronger delocalization of HOMO and LUMO together with bandgap narrowing by Fe(II) and $\mathrm{S}$ codoping facilitates the photoexcitation and migration of photoinduced charge carriers, thus enhancing the photocatalytic performance. The experimental and theoretical results confirm that the band structure of $\mathrm{g}-\mathrm{C}_{3} \mathrm{~N}_{4}$ could be tuned via $\mathrm{Fe}(\mathrm{II})+\mathrm{S}$ doping, thus improving the photocatalytic activity.

\section{Author contributions}

The manuscript was written through contributions of all authors. All authors have given approval to the final version of the manuscript.

\section{Conflicts of interest}

There are no conflicts to declare.

\section{Acknowledgements}

This work was financially supported by the National Natural Science Foundation of China (Grant No. 21173170).

\section{References}

1 A. Fujishima and K. Honda, Electrochemical photolysis of water at a semiconductor electrode, Nature, 1972, 238, 37-38.

2 X. Wang, K. Maeda, A. Thomas, K. Takanabe, G. Xin, J. M. Carlsson, K. Domen and M. Antonietti, A metal-free polymeric photocatalyst for hydrogen production from water under visible light, Nat. Mater., 2009, 8, 76-80.

3 E. Kroke, M. Schwarz, E. Horath-Bordon, P. Kroll, B. Noll and A. D. Norman, Tri-s-triazine derivatives. Part I: From trichloro-tri-s-triazine to graphitic $\mathrm{C}_{3} \mathrm{~N}_{4}$ structures part II: Alkalicyamelurates $\mathrm{M}_{3}\left[\mathrm{C}_{6} \mathrm{~N}_{7} \mathrm{O}_{3}\right], \mathrm{M}=\mathrm{Li}, \mathrm{Na}, \mathrm{K}, \mathrm{Rb}, \mathrm{Cs}, \mathrm{New}$ J. Chem., 2002, 26, 508-512.

4 W. J. Ong, L. L. Tan, Y. H. Ng, S. T. Yong and S. P. Chai, Graphitic carbon nitride $\left(\mathrm{g}-\mathrm{C}_{3} \mathrm{~N}_{4}\right)$-based photocatalysts for artificial photosynthesis and environmental remediation: are we a step closer to achieving sustainability?, Chem. Rev., 2016, 116, 7159-7329.

5 P. Martín-Ramos, J. Martín-Gil, R. C. Dante, F. Vaquero, R. M. Navarro and J. L. G. Fierro, A simple approach to synthesize $\mathrm{g}-\mathrm{C}_{3} \mathrm{~N}_{4}$ with high visible light photoactivity for hydrogen production, Int. J. Hydrogen Energy, 2015, 40, 7273-7281.

6 Y. Shiraishi, S. Kanazawa, Y. Sugano, D. Tsukamoto, H. Sakamoto, S. Ichikawa and T. Hirai, Highly selective production of hydrogen peroxide on graphitic carbon nitride $\left(\mathrm{g}-\mathrm{C}_{3} \mathrm{~N}_{4}\right)$ photocatalyst activated by visible light, $A C S$ Catal., 2014, 4, 774-780.

7 Y. Cui, Z. Ding, P. Liu, M. Antonietti, X. Fu and X. Wang, Metal-free activation of $\mathrm{H}_{2} \mathrm{O}_{2}$ by $\mathrm{g}-\mathrm{C}_{3} \mathrm{~N}_{4}$ under visible light 
irradiation for the degradation of organic pollutants, Phys. Chem. Chem. Phys., 2012, 14, 1455-1462.

8 H. Shi, G. Chen, C. Zhang and Z. Zou, Polymeric g- $\mathrm{C}_{3} \mathrm{~N}_{4}$ Coupled with $\mathrm{NaNbO}_{3}$ nanowires toward enhanced photocatalytic reduction of $\mathrm{CO}_{2}$ into renewable fuel, ACS Catal., 2014, 4, 3637-3643.

9 Z. Zhao, Y. Sun and F. Dong, Graphitic carbon nitride based nanocomposites: a review, Nanoscale, 2015, 7, 15-37.

$10 \mathrm{~J}$. Wen, J. Xie, X. Chen and X. Li, A review on g- $\mathrm{C}_{3} \mathrm{~N}_{4}$-based photocatalysts, Appl. Surf. Sci., 2017, 391, 72-123.

11 J. Gao, J. Miao, P. Z. Li, W. Y. Teng, L. Yang, Y. Zhao, B. Liu and Q. Zhang, A p-type Ti(rv)-based metal-organic framework with visible-light photo-response, Chem. Commun., 2014, 50, 3786-3788.

12 J. P. Wang, J. Cong, H. Xu, J. M. Wang, H. Liu, M. Liang, J. Gao, Q. Ni and J. Yao, Facile gel-based morphological control of $\mathrm{Ag} / \mathrm{g}-\mathrm{C}_{3} \mathrm{~N}_{4}$ porous nanofibers for photocatalytic hydrogen generation, ACS Sustainable Chem. Eng., 2017, 5, 10633-10639.

13 S. C. Yan, Z. S. Li and Z. G. Zou, Photodegradation of rhodamine $\mathrm{B}$ and methyl orange over boron-doped $g-\mathrm{C}_{3} \mathrm{~N}_{4}$ under visible light irradiation, Langmuir, 2010, 26, 38943901.

14 J. Li, B. Shen, Z. Hong, B. Lin, B. Gao and Y. Chen, A facile approach to synthesize novel oxygen-doped $\mathrm{g}-\mathrm{C}_{3} \mathrm{~N}_{4}$ with superior visible-light photoreactivity, Chem. Commun., 2012, 48, 12017-12019.

15 Y. Zhou, L. Zhang, J. Liu, X. Fan, B. Wang, M. Wang, W. Ren, J. Wang, M. Li and J. Shi, Brand new P-doped $g-\mathrm{C}_{3} \mathrm{~N}_{4}$ : enhanced photocatalytic activity for $\mathrm{H}_{2}$ evolution and rhodamine $\mathrm{B}$ degradation under visible light, J. Mater. Chem. A, 2015, 3, 3862-3867.

16 L. Ge, C. Han, X. Xiao, L. Guo and Y. Li, Enhanced visible light photocatalytic hydrogen evolution of sulfur-doped polymeric g- $\mathrm{C}_{3} \mathrm{~N}_{4}$ photocatalysts, Mater. Res. Bull., 2013, 48, 3919-3925.

$17 \mathrm{~S} . \mathrm{Hu}, \mathrm{R}$. Jin, G. Lu, D. Liu and J. Gui, The properties and photocatalytic performance comparison of $\mathrm{Fe}^{3+}$-doped $\mathrm{g}$ $\mathrm{C}_{3} \mathrm{~N}_{4}$ and $\mathrm{Fe}_{2} \mathrm{O}_{3} / g-\mathrm{C}_{3} \mathrm{~N}_{4}$ composite catalysts, RSC Adv., 2014, 4, 24863.

18 M. Fan, C. Song, T. Chen, X. Yan, D. Xu, W. Gu, W. Shi and L. Xiao, Visible-light-drived high photocatalytic activities of $\mathrm{Cu} / \mathrm{g}-\mathrm{C}_{3} \mathrm{~N}_{4}$ photocatalysts for hydrogen production, $R S C$ Adv., 2016, 6, 34633-34640.

19 L. Chen, Y. Man, Z. Chen and Y. Zhang, $\mathrm{Ag} / \mathrm{g}-\mathrm{C}_{3} \mathrm{~N}_{4}$ layered composites with enhanced visible light photocatalytic performance, Mater. Res. Express, 2016, 3, 115003.

20 J. Xue, S. Ma, Y. Zhou, Z. Zhang and M. He, Facile photochemical synthesis of $\mathrm{Au} / \mathrm{Pt} / \mathrm{g}-\mathrm{C}_{3} \mathrm{~N}_{4}$ with plasmonenhanced photocatalytic activity for antibiotic degradation, ACS Appl. Mater. Interfaces, 2015, 7, 9630-9637.

21 S. Kumar, A. Baruah, S. Tonda, B. Kumar, V. Shanker and B. Sreedhar, Cost-effective and eco-friendly synthesis of novel and stable $\mathrm{N}$-doped $\mathrm{ZnO} / \mathrm{g}-\mathrm{C}_{3} \mathrm{~N}_{4}$ core-shell nanoplates with excellent visible-light responsive photocatalysis, Nanoscale, 2014, 6, 4830-4842.
$22 \mathrm{H}$. Yan and $\mathrm{H}$. Yang, $\mathrm{TiO}_{2}-\mathrm{g}-\mathrm{C}_{3} \mathrm{~N}_{4}$ composite materials for photocatalytic $\mathrm{H}_{2}$ evolution under visible light irradiation, J. Alloys Compd., 2011, 509, L26-L29.

23 J. Zhang, Y. Wang, J. Jin, J. Zhang, Z. Lin, F. Huang and J. Yu, Efficient visible-light photocatalytic hydrogen evolution and enhanced photostability of core/shell CdS $/ \mathrm{g}-\mathrm{C}_{3} \mathrm{~N}_{4}$ nanowires, ACS Appl. Mater. Interfaces, 2013, 5, 10317-10324.

24 J. Wang, H. Xu, X. Qian, Y. Dong, J. Gao, G. Qian and J. Yao, Direct synthesis of porous nanorod-type graphitic carbon nitride/CuO composite from Cu-melamine supramolecular framework towards enhanced photocatalytic performance, Chem.-Asian J., 2015, 10, 1276-1280.

25 R. You, H. Dou, L. Chen, S. Zheng and Y. Zhang, Graphitic carbon nitride with $\mathrm{S}$ and $\mathrm{O}$ codoping for enhanced visible light photocatalytic performance, $R S C A d v$., 2017, 7, 1584215850.

26 J. Gao, Y. Wang, S. Zhou, W. Lin and Y. Kong, A Facile OneStep Synthesis of Fe-Doped $\mathrm{g}-\mathrm{C}_{3} \mathrm{~N}_{4}$ Nanosheets and Their Improved Visible-Light Photocatalytic Performance, ChemCatChem, 2017, 9, 1708-1715.

27 X. Li, J. Zhang, L. Shen, Y. Ma, W. Lei, Q. Cui and G. Zou, Preparation and characterization of graphitic carbon nitride through pyrolysis of melamine, Appl. Phys. A, 2008, 94, 387-392.

28 Q. Liu, Y. Guo, Z. Chen, Z. Zhang and X. Fang, Constructing a novel ternary $\mathrm{Fe}(\mathrm{III}) / \mathrm{graphene} / \mathrm{g}-\mathrm{C}_{3} \mathrm{~N}_{4}$ composite photocatalyst with enhanced visible-light driven photocatalytic activity via interfacial charge transfer effect, Appl. Catal., B, 2016, 183, 231-241.

29 Y. Yang, Y. Guo, F. Liu, X. Yuan, Y. Guo, S. Zhang, W. Guo and M. Huo, Preparation and enhanced visible-light photocatalytic activity of silver deposited graphitic carbon nitride plasmonic photocatalyst, Appl. Catal., B, 2013, 142143, 828-837.

$30 \mathrm{~L}$. Ge and C. Han, Synthesis of MWNTs $/ \mathrm{g}-\mathrm{C}_{3} \mathrm{~N}_{4}$ composite photocatalysts with efficient visible light photocatalytic hydrogen evolution activity, Appl. Catal., B, 2012, 117-118, 268-274.

31 Y. Qi, W. Wu, L. Han, H. Qu, X. Han, A. Wang and J. Xu, Using TG-FTIR and XPS to understand thermal degradation and flame-retardant mechanism of flexible poly(vinyl chloride) filled with metallic ferrites, J. Therm. Anal. Calorim., 2015, 123, 1263-1271.

32 X. Zhang, X. Xie, H. Wang, J. Zhang, B. Pan and Y. Xie, Enhanced photoresponsive ultrathin graphitic-phase $\mathrm{C}_{3} \mathrm{~N}_{4}$ nanosheets for bioimaging, J. Am. Chem. Soc., 2013, 135, 18-21.

33 S. Zhang, J. Li, M. Zeng, J. Li, J. Xu and X. Wang, Bandgap engineering and mechanism study of nonmetal and metal ion codoped carbon nitride: $\mathrm{C}+\mathrm{Fe}$ as an example, Chem.Eur. J., 2014, 20, 9805-9812.

34 B. Lindberg, K. Hamrin, E. Kloster-Jensen, R. Stølevik and P. Werner, Substituent Effects of Sulfur Groups III. The Influence of Conjugation on ESCA Spectra of Sulfur Substituted Nitrobenzenes, Acta Chem. Scand., 1970, 24, 3661-3671. 
35 B. J. Lindberg, K. Hamrin, G. Johansson, U. Gelius, A. Fahlman, C. Nordling and K. Siegbahn, Molecular spectroscopy by means of ESCA II. Sulfur compounds. Correlation of electron binding energy with structure, Phys. Scr., 1970, 1, 286-289.

36 C. Miranda, H. Mansilla, J. Yáñez, S. Obregón and G. Colón, Improved photocatalytic activity of $\mathrm{g}-\mathrm{C}_{3} \mathrm{~N}_{4} / \mathrm{TiO}_{2}$ composites prepared by a simple impregnation method, J. Photochem. Photobiol., A, 2013, 253, 16-21.

37 F. He, G. Chen, Y. Zhou, Y. Yu, Y. Zheng and S. Hao, Facile synthesis of mesoporous $\mathrm{g}-\mathrm{C}_{3} \mathrm{~N}_{4}$ with highly enhanced photocatalytic $\mathrm{H}_{2}$ evolution performance, Chem. Commun., 2015, 51, 16244-16246.

$38 \mathrm{Z}$. Li, C. Kong and G. Lu, Visible photocatalytic water splitting and photocatalytic two-electron oxygen formation over Cu- and Fe-doped g- $\mathrm{C}_{3} \mathrm{~N}_{4}, J$. Phys. Chem. C, 2015, 120, 56-63.

39 H. J. Kong, D. H. Won, J. Kim and S. I. Woo, Sulfur-doped g$\mathrm{C}_{3} \mathrm{~N}_{4} / \mathrm{BiVO}_{4}$ composite photocatalyst for water oxidation under visible light, Chem. Mater., 2016, 28, 1318-1324.

40 K. Wang, Q. Li, B. Liu, B. Cheng, W. Ho and J. Yu, Sulfurdoped $\mathrm{g}-\mathrm{C}_{3} \mathrm{~N}_{4}$ with enhanced photocatalytic $\mathrm{CO}_{2}$-reduction performance, Appl. Catal., B, 2015, 176-177, 44-52.

41 J. Kou, Z. Li, Y. Yuan, H. Zhang, Y. Wang and Z. Zou, Visiblelight-induced photocatalytic oxidation of polycyclic aromatic hydrocarbons over tantalum oxynitride photocatalysts, Environ. Sci. Technol., 2009, 43, 2919-2924.
42 A. Yamakata, A. T. Ishibashi and H. Onishi, Electron- and hole-capture reactions on $\mathrm{Pt} / \mathrm{TiO}_{2}$ photocatalyst exposed to methanol vapor studied with time-resolved infrared absorption spectroscopy, J. Phys. Chem. B, 2002, 106, 91229125.

43 M. Mrowetz, W. Balcerski, A. J. Colussi and M. R. Hoffmann, Oxidative power of nitrogen-doped $\mathrm{TiO}_{2}$ photocatalysts under visible illumination, J. Phys. Chem. B, 2004, 108, 17269-17273.

44 G. Liu, P. Niu, L. Yin and H. M. Cheng, Alpha-sulfur crystals as a visible-light-active photocatalyst, J. Am. Chem. Soc., 2012, 134, 9070-9073.

45 J. Cui, S. Liang, X. Wang and J. Zhang, First principle modeling of oxygen-doped monolayer graphitic carbon nitride, Mater. Chem. Phys., 2015, 161, 194-200.

46 Q. Zheng, D. P. Durkin, J. E. Elenewski, Y. Sun, N. A. Banek, L. Hua, H. Chen, M. J. Wagner, W. Zhang and D. Shuai, Visible-light-responsive graphitic carbon nitride: rational design and photocatalytic applications for water treatment, Environ. Sci. Technol., 2016, 50, 12938-12948.

47 S. Stolbov and S. Zuluaga, Sulfur doping effects on the electronic and geometric structures of graphitic carbon nitride photocatalyst: insights from first principles, $J$. Phys.: Condens. Matter, 2013, 25, 085507.

48 Y. Oh, J. O. Hwang, E. S. Lee, M. Yoon, V. D. Le, Y. H. Kim, D. H. Kim and S. O. Kim, Divalent Fe atom coordination in two-dimensional microporous graphitic carbon nitride, ACS Appl. Mater. Interfaces, 2016, 8, 25438-25443. 